\title{
POSSIBILITY OF IMPROVING GROWTH, YIELD AND BUNCH QUALITY OF BLACK MONUKKA AND RED GLOBE GRAPEVINES THROUGH THE APPLICATION OF SOME SUMMER PRUNING PRACTICES
}

Abd El-Wahab, M. A.; Hanaa A. El-Helw and Basma M. Selim Viticulture Dept., Hort. Res. Instit., Agric. Res. Center, Giza, Egypt

\begin{abstract}
This study was carried out for two successive seasons (2007 \& 2008) in a private vineyards located at El-Khatatba, Menoufiya governorate; to study on the possibility of improving vegetative growth, yield and bunch quality through the application of some summer pruning practices on Black Monukka and Red Globe grapevines. The chosen vines were ten-year-old, grown in a sandy loam soil, spaced at $2 \times 3$ meters apart, irrigated by the drip irrigation system, canepruned and trellised by the double " $Y$ " shape system. Eight treatments were applied as follows; pinching the main shoots before the beginning of bloom and removing laterals, pinching the main shoots before the beginning of bloom and topping laterals to 4-5 leaves, pinching the main shoots before the beginning of bloom and maintaining laterals, defoliation (removal of leaves beneath the clusters at veraison stage), pinching the main shoots and removing laterals + defoliation, pinching the main shoots and topping laterals to 4-5 leaves + defoliation as well as pinching the main shoots and maintaining laterals + defoliation, in addition to control (untreated vines).

The results showed that all treatments, except for defoliation treatment was effective in increasing number of bunches/vine, average bunch weight and yield. All pinching treatments alone or combined with defoliation treatment improved the physical characteristics of bunches, physical and chemical properties of berries, morphological characteristics of vegetative growth, leaf content of total chlorophyll and cane content of total carbohydrates as compared with control. Vines treated with pinching the main shoots, maintaining laterals accompanied with defoliation resulted in a great stimulation of all the studied parameters. On the other hand, control was found to record the minimum values of these characters.

The economical study indicated that vines treated with pinching the main shoots, maintaining laterals accompanied with defoliation of Black Monukka and Red Globe grapevines gave the highest net income as compared to the control.
\end{abstract}

\section{INTRODUCTION}

Black Monukka grapevines are known to have a relatively high vine vigour in relation to yield (Marawad, 2002). The quality of the clusters and berries is not rather good; since this cultivar is characterized by the production of medium berries and large and loose bunches which is negatively reflected on bunch quality.

Red Globe grapevines are characterized by having a considerably low vine vigour, which is not proportion to yield (Gasser, 2006). The good production of yield of this cultivar faces some challenges; depression of vegetative growth, increasing the possibility of berry exposure to sunburn damage and irregular colouration of the berry, there defects are undoubtedly reflected on reducing bunch quality. 


\section{Abd El-Wahab, M. A. et al.}

Summer pruning can be used as a useful means for maintaining vine balance between vegetative growth and productivity. For low to high vigour vineyards, summer pruning on fruit zone and leaf removal may be sufficient to improve the microclimate of the vine (Freese, 1988). Summer pruning is considered as an important horticultural practice already carried out in most of vineyards. It gains its importance from the fact that it is a complementary process for the preceding winter pruning and a preparatory practice for the subsequent one. Neglecting or carrying out summer pruning incorrectly has been accompanied with undesirable influence on the yield and fruit quality of the current year besides the following one. Many workers reviewed the effect of summer pruning on growth and fruiting of various grape cvs. They emphasized the necessity of summer pruning for enhancing growth and production of grapes (Reynolds. 1989; Wolf et al., 1990; Abd El-Wahab, et al., 1997, and Alia et al., 2001)

Shoot pinching has a definite place as a principal element of summer pruning practices, it is mainly done to regulate the growth, and provide better ventilation and light interception into the vine canopy; since this technique has been found to increase carbohydrate content of the shoots which was reflected on bud fertility, yield and its components and fruit quality of various grape cultivars; Abd El-Wahab, et al., (1997), Ibrahim et al., (2001), Lorenzo et al., (2001) and Omar (2004).

Defoliation or leaf removal in the fruiting zone facilitates air movement and reduces disease incidence (Gulber and Marois, 1987). By ameliorating fruit exposure to sunlight, it also contributes to improving fruit quality (Smart, 1987). Fruits well exposed to sunlight generally exhibit higher concentrations of sugars and lower acidity in grape juice compared to those ripened in dense canopy shade (Kliewer et al., 1988). It is of utmost importance that clusters should be exposed to sunlight during ripening for obtaining the best colouration of berries (Dokoozlian et al., 1995). Leaf removal as a canopy management practice is an important tool for improving the microclimate inside the grapevine canopy especially in the fruiting zone Caspari, et al., (1998). Experimental data indicate that defoliation increases the photosynthetic intensity of the remaining leaves and stimulates the assimilate export [Candolfi-Vasconcelos (1994) and Koblet et al., (1996)]. Some reports mentioned that partial defoliation of plants enhanced the efflux of assimilates from the remaining leaves [Thorne and Koller, (1974); Streeter et al., 1980 and Koblet et al., (1996)]. Defoliation or removal of 2-3 leaves from the base of the cluster has been used commercially to allow more light to enter the cluster area that was reflected on enhancing coloration (Abd El-Ghany et al., 2005)

The goal of this study was to improve vegetative growth, yield and bunch quality through the application of some summer pruning practices on Black Monukka and Red Globe grapevines. 


\section{MATERIALS AND METHODS}

This investigation was conducted in a private vineyard located at ElKhatatba, Menoufiya governorate on mature Black Monukka and Red Globe grapevines. The study extended for two successive seasons (2007 and 2008). The vines were 10-year-old, grown in a sandy loam soil, spaced at $2 \times 3$ meters apart, irrigated by the drip irrigation system, cane-pruned and trellised by the " $Y$ " shape system. The vines were pruned during the second week of January for the two seasons of the study so as to leave (6 canes X 12 buds/cane). One hundred ninety two uniform vines were chosen on the basis their growth depending on weight of prunings and trunk diameter of the vine as indirect estimates for vine vigour. Each six vines acted as a replicate and each four replicates were treated by one of the following treatments for each cultivar under study.

Eight treatments were applied as follows:

1. Control (untreated vines).

2. Pinching the main shoots (by cutting off $2-3 \mathrm{~cm}$. of the shoot tip) before the beginning of bloom and removing laterals (PR)

3. Pinching the main shoots before the beginning of bloom and topping laterals to $4-5$ leaves (PT)

4. Pinching the main shoots before the beginning of bloom and maintaining laterals (PM)

5. Defoliation (by removal of leaves beneath the clusters at veraison stage) (D)

6. $P R+D \quad 7 . P T+D \quad 8 . P M+D$

The following parameters were measured to evaluate the tested treatments:-

Representative random samples of six bunches/vine were harvested at maturity when TSS reached about $16-17 \%$ according to Tourky et al., (1995). The following characteristics were determined:

1. Yield and physical characteristics of bunches:

Yield/vine $(\mathrm{kg})$ was determined as number of bunches/vine $X$ average bunch weight $(\mathrm{g})$. Average bunch weight $(\mathrm{g})$ and average bunch dimensions (length and width) $(\mathrm{cm})$ were also determined.

2. Physical properties of berries:

Average berry weight $(\mathrm{g})$, average berry size $(\mathrm{cm} 3)$ and average berry dimensions (length and diameter) $(\mathrm{cm})$ were determined.

3. Chemical properties of berries:

Total soluble solids (T.S.S.) percentage in berry juice was determined by hand refractometer and total titratable acidity expressed as tartaric acid (\%) was determined according to (A.O.A.C. 1985). Hence TSS /acid ratio and total anthocyanin of the berry skin $(\mathrm{mg} / 100 \mathrm{~g}$ fresh weight) according to Husia et al., (1965) were calculated.

4. Some characteristics of vegetative growth

At growth cessation, the following morphological and chemical determinations were carried out on 4 shoots / the considered vine:

1- Average shoot diameter $(\mathrm{cm})$. 
Abd El-Wahab, M. A. et al.

2- Average leaf area $\left(\mathrm{cm}^{2}\right)$ of the apical $5^{\text {th }}$ and $6^{\text {th }}$ leaves using a $\mathrm{Cl}-203$ Laser Area-meter made by CID, Inc., Vancouver, USA.

3- Coefficient of wood ripening: this was calculated by dividing length of the ripened part of the shoot by the total length of the shoot according to Bouard (1966).

4- Weight of prunings $(\mathrm{Kg})$ at dormancy period (winter pruning).

5- Leaf content of total chlorophyll and cane content of total carbohydrates

1-Leaf content of total chlorophyll was measured by using nondestructive Minolta chlorophyll meter SPAD 502 of the apical 5th and the 6th leaves (Wood et al., 1992).

2-Cane content of total carbohydrates (\%) was measured according to (Smith et al., 1956).

- Statistical analysis:

The complete randomized block design was adopted for this experiment. The statistical analysis of the present data was carried out according to Snedecor and Chocran (1972). Averages were compared using the new L.S.D. values at $5 \%$ level. Percentages were transformed by a certain equation prior to the statistical analysis, and thereafter percentages were presented with statistical letters.

\section{RESULTS AND DISCUSSION}

\section{Yield and bunch physical characteristics:}

Data in (Table, 1) revealed that all summer pruning treatments had positively affected the yield/vine and bunch weight as compared with untreated vines (control) in both seasons for the two cultivars under study. The maximum values were recorded on vines subjected to pinching the main shoots and maintaining laterals accompanied with defoliation. The beneficial effect of summer pruning treatments on the yield could be ascribed mainly to the increase in bunch weight in the first season and the increase of number of bunches /vine beside the increase in bunch weight in the second season.

The positive effect of pinching treatments on increasing number of bunches/vine can be explained through the following facts: the actively growing shoot tips compete with the developing inflorescences for the nutrient assimilates.

During bloom time, the leaves in the mid and upper shoot section export carbohydrates to the shoot tip. After pinching, the direction of translocation is reversed instead of moving up to the shoot tip, assimilates are diverted downwards and made available to the developing inflorescences (Quintan and Weaver (1970), Hunter and Visser (1988)). Therefore, number of bunches increase with the increase in coefficient of bud fertility and high accumulation content of the reserved materials especially carbohydrates in the shoots besides the temporary cessation of the growth of the main shoots which aids in the redistribution of assimilates (Ahmed, 1985). In addition, the favourable effect of laterals is manifested promotion the development of embryonic shoot growth and the increase of cluster number inside the winter bud (Winkler, 1965). 
J. Agric. Sci. Mansoura Univ., 34 (4), April, 2009 
Abd El-Wahab, M. A. et al.

As far as bunch dimensions are concerned, it is evident that all summer pruning treatments had significantly increased bunch dimensions as compared with the untreated vines. Pinching the main shoots and maintaining laterals accompanied with defoliation gave the best results in comparison with control in both seasons for the two cultivars.

These results are in harmony with the finding of Abd El-Wahab, et al., (1997) and Ibrahim et al., (2001) who mentioned that pinching the main shoots and maintaining laterals resulted in the highest average number of bunches/vine, weight of bunches and yield.

2. Physical properties of berries:

Positive effects attributed to summer pruning treatments were also evident on physical characteristics of berries i.e. berry weight, size, length and diameter as compared to the control in both seasons for the two cultivars under study (Table, 2). The highest values of those parameters were detected in case of vines treated with pinching the main shoots and maintaining laterals accompanied with defoliation.

The increase in berry weight and dimensions observed in summer pruning treatments can be interpreted in view of the fact that these treatments lead to the increase in photosynthetic activity of leaves. As a consequence of that, immigration of assimilates from leaves towards berries is enhanced (Winkler, 1965). With respect to defoliation, late leaf removal (at veraison stage) is related to the activation of photosynthesis inside the canopy of the vine through increasing light penetration and temperature, which induces an increase in sugars in the berries raising its osmotic pressure and attraction force of water, thus improving physical berry properties (Omar, 2005) .

These results are in accordance with those obtained by Abd ElWahab et al., (1997) and Ibrahim et al., (2001) who showed that head suckering and pinching the main shoots and maintaining laterals resulted in the highest average berry weight, berry size and berry dimensions.

3. Chemical properties of berries:

Results presented in (Table 3 ) revealed that all berry chemical characteristics; i.e. TSS, Acidity, TSS/acid ratio and anthocyanin content of berry skin were significantly affected by all summer pruning treatments compared with untreated vines in both seasons for the two cultivars under study. Vines treated with pinching the main shoots and maintaining laterals accompanied with defoliation followed by pinching the main shoots and topping laterals to 4-5 leaves accompanied with defoliation resulted in the highest values of TSS percentage, TSS/acid ratio, anthocyanin content in berry skin and the lowest acidity of the juice as compared to the untreated vines (control).

The positive influence of summer pruning treatments on berry chemical properties i.e. TSS\%, acidity\%, TSS/acid ratio and anthocyanin content of berry skin in the grape juice could be attributed to that removing shoot tips promotes lateral shoot growth at the nodes closer to the excised tip. Lateral shoots developed during the period of active shoot growth become net exporters of carbohydrates. 
J. Agric. Sci. Mansoura Univ., 34 (4), April, 2009

2

3283 
Abd El-Wahab, M. A. et al.

3

3284 
They provide an additional photo-assimilating surface to support their own growth and export the surplus to the main shoot, contributing to fruit ripening and increasing anthocyanins content of berry skin. The most efficient leaves during ripening are located at the top of the canopy and those arising from lateral shoots (Wolf et al., 1986 and CandolfiVasconcelos and Koblet, 1994). Closely related to this topic is the work of Ali et al., (2006) who found that these findings can be interpreted as summer pruning might increase the intensity of photosynthesis in the leaves situated in the section of clusters. This, by its turn, enhanced the immigration of assimilates from leaves towards clusters during the process of ripening. With respect to defoliation, Shading has been identified as a major factor in reducing grapevine fruit quality (Smart, 1985). On the other hand, summer pruning helps in ameliorating fruit quality by more exposure to sunlight and generally exhibiting higher concentrations of sugars and lower acidity in grape juice compared to those ripened in dense canopy shade (Kliewer et al. 1988). Recently, (Omar, 2005) reported that late leaf removal allows the light to penetrate the canopy of the vine resulting in an increase in the photosynthetic activity of the leaves inside the canopy and permits air circulation raising temperature inside the canopy, consequently, ripening is promoted through the positive influence on grape composition i.e. increasing TSS and decreasing acidity.

These results agree with the findings of Wang (1989), Abd ElWahab, et al., (1997) and Ibrahim et al., (2001) who ensured that head suckering and pinching the main shoots and maintaining laterals resulted in the highest percentages of TSS and TSS/acid ratio and the lowest acidity of berry juice.

4. Some characteristics of vegetative growth

All summer pruning treatments were found to improve the characteristics of vegetative growth parameters (expressed as average shoot diameter and average leaf area), coefficient of wood ripening and weight of prunings as compared with untreated vines in both seasons for the two cultivars under study (Table, 4). The highest values of those parameters were detected in case of vines treated with pinching the main shoots and maintaining laterals accompanied with defoliation.

The positive influence of the conducted treatments was previously supported by Abd El-Wahab et al., (1997), Ibrahim et al., (2001) Lorenzo et al., (2001) who stated that head suckering and pinching the main shoots and maintaining laterals resulted in the highest values of vegetative growth parameters. With respect to defoliation, late leaf removal (at veraison stage) increased the formation of laterals and production of photosynthetically and physiologically efficient leaf area which increased root density (Hunter and Le Roux, 1992) resulting in an appreciable increase in nutrient absorption and translocation of more carbohydrates to vegetative growth (Hunter and Visser, 1990).

5- Leaf content of total chlorophyll and cane content of total carbohydrates

Data presented in (Table, 5) revealed that leaf content of total chlorophyll and cane content of total carbohydrates were significantly 


\section{Abd El-Wahab, M. A. et al.}

increased by all summer pruning treatments compared with untreated vines in both seasons for the two cultivars under study. The highest values of those parameters were detected in case of vines treated with pinching the main shoots and maintaining laterals accompanied with defoliation.

The relative increase in total carbohydrate content of canes observed in summer pruning treatments may be attributed to the high rate of shoot growth and wood ripening, since there existed a highly positive correlation between carbohydrate accumulation in the canes and the degree of wood ripening, in addition to the increase in the intensity of photosynthesis in leaves as well as the great accumulation of organic and mineral nutrients in favor of the rest tissues of the vines (Winkler, 1965). In addition, Summer pruning increases solar radiation received by the leaves in the interior canopy, which by its turn increases photosynthetic activity of the leaves and consequently carbohydrate accumulation (Kliewer, 1981). Shoot tipping improves the movement of photosynthetic towards the main shoot via removing the part of shoot tip, which consumes photosynthetic, also laterals which grow on the main shoot become exporter of photosynthetic to the main shoot (Abd ElGhany et al., 2005).

These results are in accordance with those obtained by Abd ElWahab et al., (1997) who found that pinching the main shoots and maintaining laterals resulted in the highest percentages of total carbohydrates in the second season.

Data illustrated in Figures $(1 \& 2 \& 3 \& 4 \& 5 \& 6)$ indicated the existence of a highly positive correlation between total chlorophyll and yield $(\mathrm{kg})$, between total chlorophyll and anthocyanin content of berry skin (mg/100g F.W.) and between total chlorophyll and cane total carbohydrates (\%) in both seasons for the two cultivars.

6- Economical justification of the recommended treatment (pinching main shoots and maintaining laterals + defoliation) compared with control:

It can be shown from the data presented in Table (6) that pinching main shoots and maintaining laterals + defoliation gave the maximum net profit compared with the control in both seasons for the two cultivars. The very slight raise in the cost of production/Feddan over control for this treatment is economically justified in view of the higher price of the yield obtained from this treatment.

From the obtained results, it can be concluded that pinching main shoots and maintaining laterals + defoliation gave the optimum results for yield, bunch quality, vegetative growth, leaf content of total chlorophyll and cane content of total carbohydrates for Black Monukka and Red Globe grapevines. 
J. Agric. Sci. Mansoura Univ., 34 (4), April, 2009

4

3287 
Abd El-Wahab, M. A. et al.

5

3288 
J. Agric. Sci. Mansoura Univ., 34 (4), April, 2009

f

3289 
Abd El-Wahab, M. A. et al.

f

3290 
J. Agric. Sci. Mansoura Univ., 34 (4), April, 2009

6

3291 


\section{REFERENCES}

Abd El-Ghany, A.A.; Omran, Yasser A.M.M. and Abd Kl-Galil, H.A. (2005): Effect of summer pruning on Thompson Seedless grapevines productivity. Assiut J. of Agric. Sci., 36(5): (167-180).

Abd El-Wahab, W.A, Mohamed. S.M. and El-Gendy, R.S. (1997): Effect of summer pruning on bud behaviour and bunch characteristics of Thompson Seedless grapevines. Bull. Fac. Agric. Univ. Cairo, 48: 351378.

Ahmed, F.F. (1985): Effect of alar as growth retardant and pinching on vegetative growth and the yield of Roomy red grapevines. Ph.D. Thesis. Fac. Agric., Minia, Univ.

Ali, M.A.K.; El-Gendy, R.S.S. and El-Morsi (2006): A study on the possibility of improving coloration of Crimson Seedless grapes under desert conditions via the application of some treatments. B- Summer pruning and girdling. Bull. Fac. Agric., Cairo Univ., 57: 723-744.

Alia H.I., Mervet A.A. and Abd EL-Hady M.A. (2001): Response of Red Roomy grapevines to summer pruning. J. Agric. Sci. Mansoura Univ., 26(9):56415649.

Association of Official Agricultural Chemists (1985): Official Methods of Analysis A. O. A. C., Benjumin Franklin Station, Washington, D. C. N. S. A. pp 440-510.

Bouard, J. (1966): Recherches physiologiques sur la vigne et en particulier pour l'aoutment des sarrments. Thesis Sc. Nat Bordeaux-France. Pp.34.

Candolfi-Vasconcelos, M.C. and Koblet, W. (1994): Influence of defoliation, rootstock, training system and leaf position on gas exchange of Point Noir grapevines. Am. J. Enol. Vitic.45: 173180.

Candolfi-Vasconcelos, M.C., Koblet, W., Howell, G.S., and Zweifel, W., (1994): Influence of Defoliation, Rootstock, Training System and Leaf Position on Gas Exchange of "Pinot Noir" Grapevines, Am. J. Enol. Vitic., vol. 30, pp. 129-141.

Caspari, H. W., Lang, A., Alspach, P. (1998): Effects of girdling and leaf removal on fruit set and vegetative growth in grape. Amer. J. of Enol. and Viticul., 49 (4): 359-366.

Dokoozlian, N.; D. Luvisi; M. Moriyama and P. Schradr (1995): Cultural practices improve colour, size of "Crimson Seedless". California Agriculture, 49 (2): 36-40.

Freese, P.P. (1988): Canopy modification and fruit composition. Proc. Second Int. Symp. Auckland, Newzealand. Nz. Soc. For Vitic. and Qenal 134-136.

Gaser, A. S.A. (2006): Evaluation of some newly-introduced grape cultivars under Egyptian conditions with special stress on some morphological characteristics. J. Agric. Sci. Mansoura Univ., 31(11): 7305-7320.

Gubler, W.D. and J.J. Marois (1987): Control of bunch rot in grape with canopy management. Plant Disease 71: 599-601.

Hunter, J.J. and D.J. Le Roux (1992): The effect of partial defoliation on development and distribution of roots of Vitis vinifera L cv. Cabernet sauvignon grafted onto rootstock 99 Richter. Am. J. Enol. Vitic.43: 71.

Hunter, J.J. and Visser, J.H. (1988): The effect of partial defoliation, leaf position and developmental stage of the vine on the photosynthetic activity of Vitis vinifera L. cv. Cabernet Sauvignon, Afr. J. Enol. Vitic., vol. 10, pp. 67-73. 
Hunter, J.J. and J. H. Visser (1990): The effect of partial defoliation on quality characteristics of Vitis vinifera L cv. Cabernet sauvignon grapes. IIReproductive growth. S. Afr. J. Enol. Vitic. 11 (1): 26-32.

Husia, C. L.; B. S. Luh and C. D. Chichester (1965): Anthocyanin in free stone peach. J. Food Science, 30: 5-12.

Ibrahim, A. H., Abd El-Karem M. A. and Abd El-Hady M. A. (2001): Response of Red Roomy grapevines to summer pruning. J. Agric. Sci. Mansoura Univ., 26 (9): 5641-5649.

Kliewer, W.M. (1981): Grapevine physiology: How does a grapevine make sugar? Leaflet 21231. division of Agricultural Sciences. Univ. Calif.

Kliewer, W.M.; J.J. Marois and A.M. Bledsoe (1988): Relative effectiveness of leaf removal, shoot positioning and trellising for improving wine grape composition. In proceedings of the second International Symposium for Cool Climatic Viticulture and Oenology 11-15 January. Auckland, New Zealand.

Koblet, W., Carmo Candolfi-Vasconcelos, M., and Keller, M., (1996): Effects of Training System, Canopy Management Practices, Crop Load and Rootstock on Grapevine Photosynthesis, Acta Hortic. (ISHS), vol. 427, pp. 133-140.

Lorenzo, R. di, Ferrante, S. and Barbagallo, M. G. (2001): Modification of source/sink ratios in Nero d'Avola (Vitis vinifera L.) grapevines in a warmdry environment. Advan. in Hort. Sci., , 15 (1/4):31-38.

Marwad, I.A. (2002): Comparative studies of five seedless grape cultivars under conditions of Qalubia governorate, Egypt. Egypt. J. Appl. Sci., 17 (1) 307326.

Omar, A. H. (2004): Summer pruning and foliar application with $\mathrm{Fe}, \mathrm{Zn}$ and $\mathrm{Mn}$ for Thompson Seedless grapevines. J. Agric. Sci. Mansoura Univ., 29(12): 7177-7189.

Omar, A. H. (2005): Partial leaf removal and its influence on microclimate and characteristics of Superior Seedless grapevines. J. Agric. Sci. Mansoura Univ., 30(7): 4073-4083.

Quintan, J.Q. and Weaver, R.J. (1970): Modification of the pattern of the photosynthate movement within and between shoots of Vitis vinifera $L$. Plant Physiol. 46:527-530.

Reynolds, A.G. (1989): Impact of pruning strategy, cluster thinning and shoot removal on growth, yield and fruit composition of low De Chaunac vines. Canadian J. plant Sci., 69(1): 260-275.

Smart, R.E. (1985): Principles of grapevine canopy management microclimate manipulation with implications for yield and quality. A review. Am. J. Enol Vitic., 36: 230-239.

Smart, R.E. (1987): Influence of light on composition and quality of grapes. Acta Horticulture, 205: 37-47.

Smith, F. Gilles, M. A. Hamilton, J. K. and Gedess, P. A. (1956): Colorimetric methods for determination of sugar and related substan. Anal. Chem. 28: 350 .

Snedecor, G. W. and Cochran. W.G. (1972): Statistical Methods . 6th ed, The lowa State Univ. . Press . Ames. , lowa, U.S.A., pp. 50

Streeter, J.C., Mederski, H.J., and Ahmad, R.A., (1980): Coupling between Photosynthesis and Nitrogen Fixation, World Soybean Res., $2^{\text {nd }}$ Conf., Proc. Builder, Col. L., pp. 129-137.

Thorne, J.H. and Koller, H.R., (1974): Influence of Assimilate Demand on Photosynthesis Diffusive Resistances, Translocation and Carbohydrate Levels of Soybean Leaves, Plant Physiol., vol. 54, pp. 201-207. 


\section{Abd El-Wahab, M. A. et al.}

Tourky, M.N., El-Shahat, S.S. and Rizk, M. H. (1995): Effect of Dormex on fruit set, quality and storage life of Thompson seedless grapes (Banati grapes) J. Agric. Sci., Mansoura Univ., 20(12): 51395151.

Wang. W.Y. (1989): Studies on forcing of Golden Muscat grapevine (Vitis vinifera $\mathrm{x}$ Vitis labrusca) II. Study of the improvement of fruiting potential and autumn-winter fruit quality . Jour. of Agric Res. of China $38(1): 42-52$ C.F. (Hort. Abst. 60:5055).

Winkler, A. (1965): General Viticulture. Univ. Calif. Press, Barkely and Loss Angeles.

Wolf, T. K.; Pool, R.M. and Mattik, L.R. (1986): Responses of young chardonnay grapevines Vitis vinifera to shoot tipping, ethephon, and basal leaf removal. Amer. J. Enol. Vitic. 37:263-268.

Wolf, T.K.; Zoechlein, B.W.; Cook, M.K. and Coreingham, C.K. (1990): Shoot topping and ethephon effects on White Riesling grapes. Amer. J. Enol. Vitic. 41(4): 330-341.

Wood, C.W., Reeves, D.W. and Himelrick, D.G. (1992): Relationships between chlorophyll meter readings and leaf chlorophyll concentration. $\mathrm{N}$ status and crop yield. A review: Proc. Agro. Soc. N.Z. 23: 1-9.

\section{إمكانية تحسين النمو والمحصول وجودة الثـار لكرمـات عنب البلاك مونوكا والرد

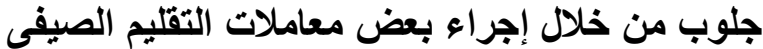

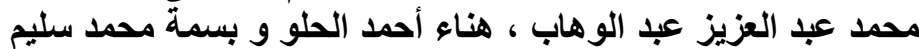

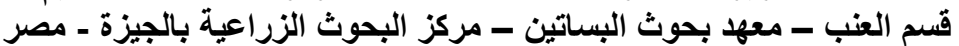

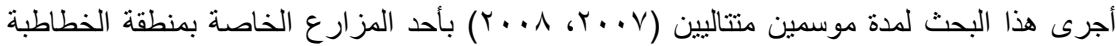

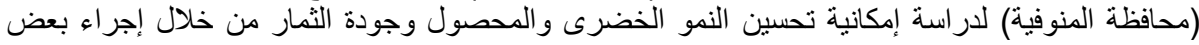

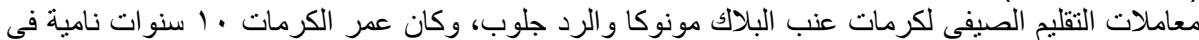

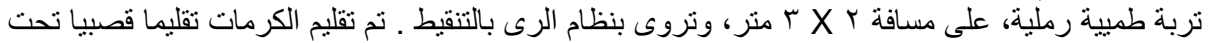

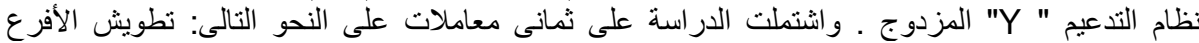

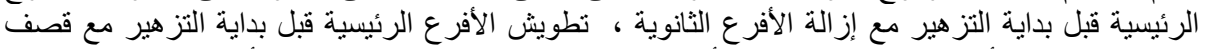

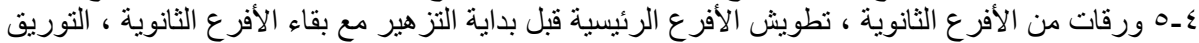

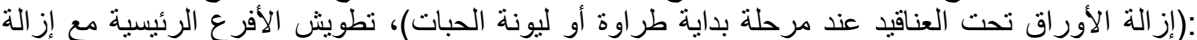

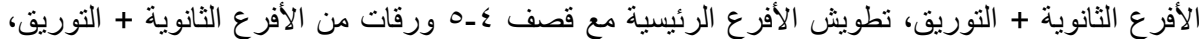

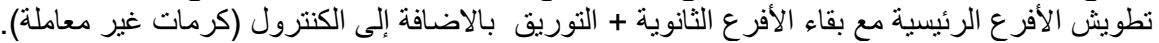

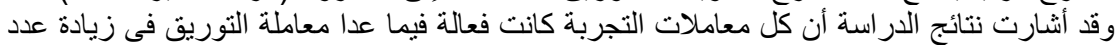

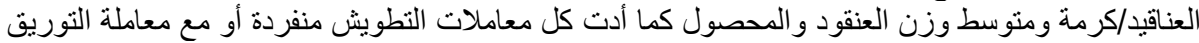

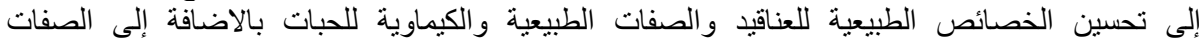

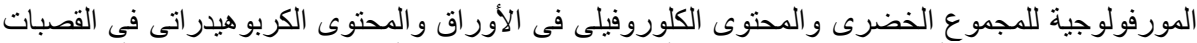

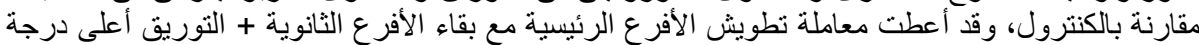

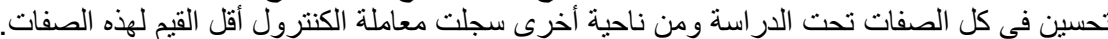

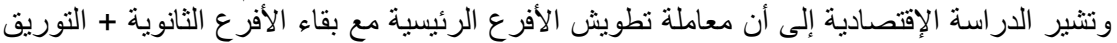

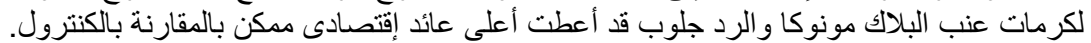

